\title{
Udo Thiel* \\ The Early Modern Subject Revisited - Responses to Barth, Lenz, Renz and Wunderlich
}

DOI 10.1515/kant-2016-0042

'Tis with our judgments as our watches, none Go just alike, yet each believes his own.

(A. Pope, An Essay on Criticism)

\begin{abstract}
Responding to comments on The Early Modern Subject, this paper focuses on a strictly limited range of issues: methodology, Descartes on consciousness, and Locke and Hume on personal identity. 1) Ursula Renz's comments prompt an explanation of the notion of development in historical studies of philosophy. 2) Contra Christian Barth, although it is difficult to determine what kind of self-relation consciousness is for Descartes on the basis of the texts, it is argued that a higher-order reading is a more plausible interpretation than a first-order reading. 3) It is shown that Locke's account of personal identity can usefully be characterized as 'subjectivist', in spite of Martin Lenz's objections. 4) And finally, in consideration of Falk Wunderlich's comments, the paper argues against both a traditional 'ontological' reading and a 'sceptical realist' interpretation of Hume's bundle theory of the mind.
\end{abstract}

Keywords: (self-)consciousness, personal identity, Descartes, Locke, Hume, historiography of philosophy

It is both a pleasure and an honour to have The Early Modern Subject (EMS) discussed by four excellent scholars of early modern philosophy. I am extremely grateful to all four contributors for their thoughtful comments and to Falk Wunderlich for organising the symposium and editing the subsequent papers. While there are, of course, critical comments concerning several points of detail, there are also areas of agreement, and the authors' very positive assessments of EMS as a whole obviously please its author. I mention this at the outset because in this paper, for reasons of space, I have to focus on our disagreements, and my

*Kontakt: Prof. Dr. Udo Thiel, Universität Graz, Institut für Philosophie, Heinrichstrasse 33/P, A-8010 Graz; udo.thiel@uni-graz.at 
responses have to be briefer than the comments deserve. The authors themselves acknowledge that, for the same reason, many thematic aspects and thinkers discussed in EMS are left untouched by their comments. These focus, apart from some larger methodological issues, only on Descartes on consciousness and Locke and Hume on personal identity.

\section{Methodological Issues (Renz)}

Ursula Renz's main concern is the very notion of development invoked in historical studies of philosophy. And indeed in the Introduction EMS makes use of that idea, outlining the "general development" of thought on self-consciousness and personal identity within early modern philosophy. What is this notion of development? The Introduction, several individual Chapters and the Conclusion make clear that this notion must not be confused with that of progress towards some goal. EMS does not assume that some kind of progressive or hierarchical structure underlies early modern discussions of self-consciousness and personal identity. It attempts, however, to identify a number of both major and minor turning points in the early modern debates about these issues. There was not just random change, but a development of thought in the sense that, for example, a thinker or group of thinkers may have adopted a new perspective on the topic; or that a philosopher may have introduced some new conceptual distinctions; or that a thinker, such as Leibniz, may even have coined some new terminology in his attempt to deal with the issue of self-consciousness.

In connection with the issue of development, Renz raises questions about the "thematic unity" and "the time period to be considered in order to account for a particular development” (Renz 538, 541-542). In terms of the former Renz asks: why the preference for self-consciousness and personal identity? Why not instead deal with other features of human subjectivity, such as the issue of agency? EMS answers this question by arguing that the former issues are more fundamental than other topics that belong to the large complex of questions relating to subjectivity (EMS 1). Some of these, such as moral and legal responsibility, are discussed at various points in EMS, and their connection to the issues of self-consciousness and identity is highlighted. Thus the thematic focus is not arbitrary but based on systematic considerations. The chosen time period for this volume is explained in EMS 1-3. To focus, then, on the early modern period when examining self-consciousness and personal identity is neither arbitrary nor "pragmatic". While it is true that thought about these issues goes back to ancient Greek and medieval philosophy, interest in the issues of self-consciousness and personal identity is 
both characteristic of and central to early modern thought. And this is an interest that continues to this day, in a form still strongly influenced by the conceptual frameworks of early modern thought. While EMS ends with Hume and his critics, it states explicitly that the debates do not end with Hume (EMS 431). Later developments are to be discussed in a separate volume. It makes sense, however, to end the present volume with the debates about Wolff and Hume and their critics because although there are many and complex continuities, the discussion in the second half of the century took new turns, for example with the strengthening of materialist metaphysics and, later, Kantian philosophy. Notwithstanding several continuities, then, the intellectual worlds of the 1720 and 1730s on the one hand and the 1770 s and the 1780 s on the other are quite distinct.

A more general issue in Renz's comments concerns her distinction between "internalism" and "externalism" in historical studies of philosophical developments (Renz 538). Renz acknowledges that these are "ideal types" and that "it goes without saying that most historians of philosophy practice a mixture of internalism and externalism". Yet then, as if EMS had to be one or the other, she asks the "interpretive question" of whether "Thiel [...] [is] an externalist or an internalist with regard to the development of the issues of (self-)consciousness and personal identity". Renz claims that EMS is verbally committed to externalism, but in fact proceeds along internalist lines. In making this claim she seems to assume that the theological context of philosophical debates which EMS examines is evidence for an internalist approach (Renz 539). This, however, is a questionable assumption. It is true that the debate about self-consciousness and personal identity develops a certain dynamic of its own, but theological and related moral and legal contexts remain relevant throughout. At various points EMS discusses those moral and legal contexts (e.g. 77-81, 130-131) and, for example, the relevance of matter theory emerging in the context of the developing experiential sciences to debates about individuation and identity (e.g. EMS 73-76). In my view, however, it would be a mistake to commit oneself 'a priori' to either an 'internalist' or an 'externalist' approach. It makes no sense to examine the coffee-house culture, say, only because one has committed oneself to externalism, if there is no evidence at all that such an examination would help in any way to illuminate abstract debates such as those about the principle of individuation. At the same time, one should of course be open to examining 'external' factors such as theological, scientific or political contexts if these turn out to be required for an understanding of philosophical positions or arguments. 


\section{Self-Consciousness in Early Modern Philosophy (Barth and Renz)}

While Renz relates her general methodological comments to the specific issue of self-consciousness, Christian Barth's remarks about consciousness in early modern philosophy involve larger methodological issues. Barth thinks that EMS is concerned with the notion of consciousness in general and with pursuing two distinct projects in this regard, one "linguistic", one "explanatory" (Barth 516). He sees nothing wrong with either project but believes that EMS makes an unwarranted move from a linguistic observation about the meaning of 'consciousness' and its cognates to an explanatory claim that what today is called "object consciousness did not play much of a role in early modern discussions" (Barth 519). There are several problems with Barth's account. First, EMS's stated focus is not consciousness in general, but the issue of self-consciousness. In order to examine the latter it of course needs to look at the former. However, other forms of consciousness such as object-consciousness are considered only in so far as they are relevant to self-relating consciousness or self-consciousness. Second, this means that EMS does not make any explicit or implicit claims about the role of object-consciousness in early modern philosophy. It certainly does not say or imply that "object-consciousness did not play much of a role in early modern discussions". Third, pace Barth, EMS does not have two projects, one linguistic, one explanatory. There is the one project that is stated explicitly in the Introduction, and in an attempt to pursue this successfully EMS takes into account several perspectives (terminological, contextual, analytical, etc.).

Renz, too, sees EMS as at least in part driven by a terminological concern. She writes that "Thiel exclusively engages with theories if and insofar as they make use of the terms 'consciousness', 'conscience', or 'conscientia'” (Renz 542). ${ }^{1}$ This

1 Renz mentions Spinoza as an example of a philosopher who discusses consciousness without using terms such as 'conscientia' and its cognates (Renz 542, and note 3), appealing to her own indeed excellent book on Spinoza for a full treatment of the issue (Renz 2010, 189-196). According to Renz, Spinoza presupposes that the mind has implicit knowledge of its own body, and this, she says, is "a similar kind of pre-reflexive knowledge to what Thiel finds in Locke's concept of consciousness" (Renz 542). Of course, EMS does not even claim that it was "Locke who first recognized the importance of pre-reflexive consciousness" (Renz 542), considering the account of thinkers such as La Forge and Arnauld (EMS 52-54). Moreover, there would still be a significant difference between Spinoza and Locke. For Locke, consciousness relates to one's own thoughts and actions, making us accountable for and concerned with them. Lastly, on Renz's own reading the notion of pre-reflective knowledge of one's own body is presupposed by Spinoza but not stated explicitly, let alone elaborated on or explained in any detail. It is not surprising, therefore, that this idea was not taken up from Spinoza in subsequent discussions. 
is false. EMS's analysis is focused on the issue of relating to one's own self, not on a particular set of terms. Indeed, EMS considers accounts that use a very different terminology from the ones cited by Renz ('virtual reflection', 'reflection', 'apperception', 'intuition', 'sentiment intérieur', etc.). Contrary to what Renz maintains, EMS nowhere states or assumes that "the development of ideas [...] necessarily correspond[s] to the development of terminology" (Renz 542), or that the use of 'consciousness' and its cognates is "the sole indicator of a thinker's interest in the issue of consciousness in early modern philosophy” (Renz 542). Nor does EMS treat consciousness and self-consciousness as "one singular feature" (Renz 543). Consciousness and self-consciousness are closely related issues, but EMS makes a point of distinguishing between the two and relating them to one another at several points, for example in the Introduction, and in the discussions of Locke, Leibniz, and Wolff, to name only a few of the relevant thinkers in this context.

Further, Renz claims that EMS “makes use” of the Heidelberg School's conception of self-consciousness in reconstructing Locke's account of consciousness (Renz 540). Indeed, she seems to think that EMS has a hidden agenda, which consists in defending the Heidelberg School's conception through a reading of Locke. These comments came as somewhat of a surprise. EMS ascribes a sameorder account of consciousness to Locke and highlights some of the advantages of the Lockean position. This is argued on the basis of textual and explanatory analysis. The Heidelberg School plays no role whatsoever in making this case. There are many present-day and earlier philosophers who discuss and even some who endorse a same-order account of consciousness without invoking or even so much as being aware of the Heidelberg School. The latter distinguishes itself not so much by a same-order account of consciousness, but by making a much stronger claim invoking the notion of a pre-reflective 'familiarity' with oneself, whatever that means precisely. In short, reading Locke's account as a same-order theory is a far cry from adopting, let alone promoting, the Heidelberg School's teachings. In fact, while a detailed discussion of the latter cannot be part of EMS, it does point to Dan Zahavi's discussion of problems with those teachings (EMS 18).

\section{Descartes on Consciousness (Barth)}

Barth's comments on Descartes begin with remarks on the term 'conscientia'. EMS argues that "Descartes [...] makes use of 'conscientia' or 'conscium esse' in the non-evaluative sense - at least in some contexts" (EMS 9). Now Barth claims (1) that EMS states that with Descartes the Latin term 'conscientia' begins to be used in this non-evaluative sense, whereas previously it was mainly used in a 
moral context, denoting conscience (Barth 516, 519f.). Barth maintains (2) that EMS provides an account of how "Descartes arrives at his new use of "conscientia”" (Barth 520). Both claims (1) and (2) are false, however. EMS does not claim that Descartes's use of 'conscientia' is new or innovative, ${ }^{2}$ and consequently there is no account in EMS of how Descartes arrives at this "new" use of 'conscientia'. Indeed, Barth himself states, correctly, that EMS discusses several non-moral uses of 'conscientia' prior to Descartes. He cites (i) the ancient use of 'conscientia', first as knowledge that one shares with someone else, and second as knowledge of something one shares 'with oneself' (EMS 8; Barth 521). Barth refers (ii) to the Scholastic conscientia theorem, which involves a non-evaluative remembering or knowledge of one's own thoughts and actions (EMS 8-9; Barth 520). EMS simply does not speculate about the origin of Descartes's use of 'conscientia' in one of these (or other) earlier non-evaluative uses of the term. Bizarrely, however, Barth asserts that according to EMS, “Descartes arrives at his new use of 'conscientia' by abstracting from the established moral use of the term” (Barth 520; see also 521), referring to EMS 9 and 43 as evidence. Yet on neither page, and indeed nowhere else in the book, can such a claim or suggestion be found. It is thus not fact but fantasy to claim that EMS gives such an account. How Barth arrived at his view that it does is a complete mystery. Barth next argues against the view he wrongly ascribes to EMS, but this is obviously a futile project, and there is no need to comment on his critique of a view that EMS does not even hold.

Turning to the nature of consciousness in Descartes, Barth acknowledges that EMS argues that "it seems difficult to determine precisely, on the basis of his writings, what kind of self-relation consciousness is" (EMS 48). Yet he asserts that EMS "eventually [...] opts for attributing a higher-order account to Descartes" (Barth 522). In fact, EMS merely argues that, although there may be passages in Descartes that can be used to support a first-order reading, the higher-order reading is more plausible (EMS 48). Barth next presents four arguments against a higherorder reading.

Barth's first argument is that "the textual evidence [...] is shaky" (Barth 522). He refers to a passage cited in EMS from the Conversation with Burman in which Descartes is reported as stating that "conscium esse est quidem cogitare et reflectere supra suam cogitationem" (AT V, 149). Barth seems to agree that this passage suggests a higher-order account but thinks it is doubtful that the passage is a "faithful presentation of Descartes's own view" because the Conversation was not composed by Descartes himself and because (Barth maintains)

2 Barth does not (and cannot) cite EMS for this thesis. Rather, he appeals to Davies 1990 (Barth 516) and ascribes this tacitly but mistakenly to EMS. 
there are no similar clear-cut passages for a higher-order reading in Descartes (Barth 522). In reply, first, no one has shown to date that the Conversation is not genuine. John Cottingham, too, to whom Barth appeals as an authority for the composition of the Conversation, argues that the work is substantially authentic as a source of Descartes's ideas. ${ }^{3}$ Second, contrary to what Barth maintains, other passages in Descartes's works support the higher-order interpretation suggested by the passage in the Conversation. There is Descartes's reply to Bourdin, cited by Barth himself as not speaking "in favour of a first-order reading” (Barth 522, footnote 14), and there is Descartes's response to Hobbes, to mention just two examples (EMS 47-48). Third, Barth himself appeals to a different passage from the Conversation in support of his own reading (Barth 523). As just noted, it would surely be a mistake to assume that this passage, but not the one about 'conscium esse', is supported by other comments elsewhere in Descartes's writings.

Barth's second argument appeals to the idea that in Descartes a higher-order account of consciousness would lead to an infinite regress (Barth 522). This problem, says Barth, is so obvious that Descartes cannot have overlooked it, and so the principle of charity demands that we not ascribe a higher-order account of consciousness to him. This, however, is hardly persuasive. Many early modern philosophers worked with some idea of consciousness without thinking through all the problems implied by that idea. Moreover, Hobbes explicitly raised the infinite-regress issue against Descartes, clearly assuming that the latter had a higher-order understanding of consciousness (EMS 48, not considered by Barth). In his response, Descartes does not take exception to Hobbes's assumption. He obviously thought that a higher-order notion of consciousness does not, in his case, lead to an infinite regress. Indeed, in the Conversation Descartes is reported as saying that "the soul is capable of thinking of more than one thing at the same time, and of continuing with a particular thought which it has" (AT V, 149; CSM III, 335; EMS 48).

Barth's third argument is that "reflectere" in the cited passage from the Conversation must denote the idea of "deliberate reflection" (Barth 522). The view that consciousness consists in deliberate reflection is, however, a "crazy position”, and one ought not to ascribe crazy views to Descartes (Barth 523). As noted, however, the comment in the Conversation has to be read in the context of the infinite regress issue. Therefore, it is not at all obvious that a notion of "deliberate reflection" is invoked here. Barth ignores the discussion in EMS of different notions of reflection in Descartes (EMS 45 and 46), arguing that Descartes does not use the terminology of 'reflexio' consistently and that "reflectere" in the rel-

3 Cottingham 1976, xvii-xviii. 
evant passage from the Conversation "should not be identified with a particular kind of thought called 'reflexive thought"' (EMS 46). A fortiori, it should not be read in terms of 'deliberate reflection'.

Barth's fourth argument is that "there is textual evidence against the higher-order account that Thiel does not address" (Barth 523). Barth focuses on two letters to Arnauld (Barth 523-524, addressed in EMS 45-46). He quotes Descartes as saying that reflective thoughts are "so linked to sensation that the two occur together and appear to be indistinguishable from each other" (AT V, 221; CSM III, 357). As Descartes speaks here of two distinct acts (only difficult to distinguish from each other, as Barth says, "from the first person perspective"), it is somewhat surprising that Barth very implausibly takes this passage to be evidence against a higher-order reading of consciousness.

\section{Locke on Personal Identity (Lenz)}

Martin Lenz is a distinguished Locke scholar, and his comment that as far as EMS's account of Locke is concerned "it is hard to find anything to disagree with" (Lenz 526) is of course very gratifying. Not wishing to challenge EMS's reading of "Locke's account personal identity or its reception", Lenz focuses on "the notion of subjectivism” that is involved in EMS's reconstruction of Locke (Lenz 527). Lenz believes that it is "not entirely clear how we should understand this characterization" in terms of subjectivism, and he raises "some worries about this label" (Lenz 527). I believe that our disagreements here concern mostly, although not exclusively, a verbal matter.

Part II of EMS (97-150) is indeed entitled “Locke's Subjectivist Revolution”. The two chapters of part II, Chapters 3 and 4 of the book, proceed to focus on two different aspects of subjectivism in Locke. The first aspect is explained in Chapter 3: (1) Locke "treats the special problem of personal identity in accordance with his general theory of identity. This is essentially a subjectivist treatment of the issue where our own concepts are crucial rather than the things themselves" (EMS 103, see also 104-105). Thus, 'subjectivism' here refers to a shift away from a primarily ontological account of identity to the view that "our concepts of those things (including persons) whose identity is in question [...] [are] regarded as crucial for dealing with problems of individuation and identity" (EMS 72). Other philosophers prior to Locke - thinkers as diverse as Johannes Clauberg, Thomas Hobbes and Robert Boyle - hinted at this position (see EMS 72-76).

The second aspect of subjectivism is discussed in Chapter 4 (EMS 121-126). Here the notion refers not to the issue of identity in general, but rather to that of 
personhood and the special issue of the identity of persons - that is, to Locke's view (2) that personal identity is not pre-given by the nature of the thinking substance, but constituted through inner consciousness. Therefore, EMS speaks of the constitutive function of consciousness for personal identity in Locke, adopting Kenneth Winkler's terminology of a "subjective constitution of the self" (EMS 122, 147).

Thus it would seem that the notion of subjectivism as understood in EMS is clear enough and is explained in sufficient detail. Indeed, the two aspects (1) and (2) of subjectivism are reflected in Lenz's own distinction between what he calls "recognitional subjectivism" and "constitutive subjectivism” (Lenz 528-529). His label of "recognitional” subjectivism for (1), however, suggests that a purely epistemic matter is at issue and that the thesis concerns only the question of what is required for our knowledge that a thing is the same at different points in time. In my view, Locke makes a stronger claim than that and argues that there can be no account of what it is for any thing to be identical over time without reference to a (sortal) concept. Still, Lenz thinks that "some doubts remain about the subjectivist status of personhood" (Lenz 530), and he argues that for Locke personal identity has objective and intersubjective features as well as the subjective ones outlined above and that therefore one should not label his theory "subjectivist".

Under the heading of "objective features" of personal identity, Lenz discusses problems that arise for Locke's account from the consideration of cases of amnesia and of mistaken self-ascriptions of actions (Lenz 530-531). I agree that such cases raise problems for Locke's view, and they are discussed in some detail in EMS (126, 130-131, 132-134, 168-189), but they raise problems quite independently of whether or not one labels Locke's account 'subjectivist'. In terms of "intersubjective features", Lenz argues that they become apparent when we look closer at Locke's theory of thought. He argues that, according to Locke, thinking is mostly thinking in language, and language is an "intersubjective or social device" (Lenz 531). It follows that "the very elements our consciousness is an inherent feature of are governed not by individual subjects but by the community we are part of" (Lenz 531). For Locke, when we steal an apple we are conscious of stealing an apple, "but our ideas of apples, and especially of stealing, are not simply subjective givens” (Lenz 531). Lenz's conclusion is that "Locke’s account of language has repercussions for the supposed subjectivity of personal identity” (Lenz 533) and that it is "questionable whether morality is truly grounded in a subjective notion of personhood, as Thiel claims" (Lenz 533).

In response, I agree completely with Lenz's account of the importance and intersubjective features of language, but I believe that this is consistent with EMS's account of personal identity and of subjectivism (1). That account does not involve a claim about the genesis of the relevant concepts and certainly does not argue 
that the criteria for identity are "simply subjective givens". EMS does not ascribe to Locke what Lenz understands subjectivism to entail, namely the "assumption that I alone can immediality grasp [...] my inner states without recourse to any external standards" (Lenz 527). And so I disagree with Lenz's conclusion. That conclusion follows only if we adopt a notion of subjectivism that is different from the one that is employed in EMS. Lenz seems in any case to accept that (2), the thesis he calls “constitutive subjectivism” (Lenz $533 \mathrm{f}$.), is applicable to Locke. This 'constitutive subjectivism' does not of course mean that all aspects of morality are constituted subjectively. Locke assumes rationality, freedom, and universal moral norms to which I must relate those actions of which I am conscious as my own. This is implied by Locke's statement that the term 'person' belongs to beings that are "capable of a Law" (Essay II.27.26, EMS 128). In short, EMS does not claim that Locke is in general to be described as “a subjectivist thinker” (Lenz 535).

Lenz suggests that I drop the label 'subjectivism'. Indeed, I am not committed to the word, and if a better label for summarizing theses (1) and (2) can be found, I would be happy to adopt it. However, if one sticks to the meaning of 'subjectivism' for theses (1) and (2) as explained in EMS, there does not seem to be any problem with the label.

\section{Hume on the Self as a Bundle of Perceptions (Wunderlich)}

Skipping over the British debate after Locke, the German tradition from Leibniz to Wolff, their followers and critics, and early eighteenth-century French material (EMS 153-380), we move on to Hume's account of the self, discussed in the last two chapters of EMS. As both the title of Wunderlich's paper and his section titles suggest, he links EMS's reading to sceptical realist readings of Hume. 'Sceptical realism' is, of course, a huge matter of debate in Hume scholarship, and Wunderlich manages with admirable clarity to weave an account of this into his comments on EMS. However, Wunderlich's references to sceptical realist readings can be misleading. As he himself acknowledges, there is a significant difference between the account given in EMS and, for example, Galen Strawson's sceptical realist account of Hume on the self. Indeed, while EMS is critical of the traditional ontological reading of Hume's bundle view of the self (the 'Old Hume'), it does not propose either that Hume, pre- or post-Appendix, affirms or is committed to the existence of a self beyond the perceptions (the 'New Hume'). EMS argues, however, that Hume does not deny the existence of a self beyond the perceptions (and it is this negative thesis that EMS shares with Strawson). 
Wunderlich presents four objections, which are directed at both the sceptical realist reading and the reading presented in EMS, obviously assuming they are valid for both. The first objection appeals to a few "passages in the identity chapter" (Wunderlich 549) that Wunderlich thinks suggest an ontological reading of the bundle theory. In fact, Wunderlich cites exactly one passage from the identity chapter. The passage in question (Treatise 252) is discussed also at EMS 387 and 404. Hume argues here that if my perceptions were removed, as "by sound sleep", I would be insensible of myself, that is to say, there would be no experiential evidence for my existence, and in that sense I "may truly be said not to exist". Hume does not say here that during "sound sleep" there is definitely no such thing that is asleep. It is not as obvious as Wunderlich seems to think, then, that this passage amounts to an endorsement of the bundle theory as an ontological truth. The passage Wunderlich cites from Hume's Of the Immortality of the Soul does not invoke the bundle view of the mind, and it is not clear that the passage can be used to ascribe this view in ontological terms to the Treatise. The third passage to which Wunderlich appeals is from Hume's Abstract and is discussed at EMS 402-403. Here, Hume says that "our several particular perceptions compose the mind" (Norton and Norton 414). But the context makes clear that this statement concerns the mind "as far as we can conceive it" (ibid.). Thus none of the passages that Wunderlich invokes speaks clearly in favour of an ontological reading of the bundle theory of the mind.

Wunderlich's second objection appeals to Treatise I.iv.5, which he admits is a rather "complicated" matter in itself (Wunderlich 550). In this section Hume argues that the notion of the mind or soul as a substance is "unintelligible", an idea that he repeats in the passage in the Abstract cited above. Wunderlich reads Hume's comments here as stating that we "positively know" that the self is not a substance. He argues further that for Hume the only possible alternative to the substance view is the bundle view, dismissing other options such as the Lockean notion of personhood. Therefore, according to Wunderlich, Hume is committed to the bundle theory as an ontological truth (Wunderlich 551). Wunderlich seems to assume that when Hume says that something is 'unintelligible', he means to say not only that it is incomprehensible, unintelligible to us, but that it cannot exist. It is not at all obvious, however, that the notion has such an ontological implication. ${ }^{4}$ With regard to the notion of the mind as a substance, Hume says that "we have no idea of substance of any kind, since we have no impression of any substance either material or spiritual. We know nothing but particular qualities and perceptions [...] So our idea of any mind is only that of particular

4 Compare Strawson 2011, 12-13. 
perceptions" (Abstract, in Norton and Norton 414; my emphases; see also EMS 402-403). Further, Wunderlich does not take into account Hume's comments in the Introduction to the Treatise where he outlines that his account of the mind is concerned not with the real nature of the mind but with the mind "only as far as experience informs" him of it (Treatise 64; EMS 421). Hume is committed to remaining agnostic about the nature of the mind beyond the experientially accessible bundle of perceptions. Even asking what the self might be beyond the perceptions makes no sense, since it is a question we cannot answer.

Having argued in objections 1 and 2 that Hume is committed to an ontological understanding of the bundle view, Wunderlich's third objection has a surprising twist in that it claims that Hume's bundle theory is "compatible with ontological agnosticism" (Wunderlich 552). Wunderlich says here that EMS is right to reject the no-ownership view of Hume's account of the self, but he argues that EMS's arguments do not work against the "proper bundle theory" that he ascribes to Hume. The "proper bundle theory", Wunderlich explains, does not claim that there is no self but holds "that the self is just what we experience: a succession of perceptions, organized by principles of association, etc., leaving open the question of real essences" (Wunderlich 552). This is the "self as far as we can tell" (ibid.). It is not clear, however, in what sense this amounts to an objection to EMS's reading of Hume. It seems, rather, a somewhat different way of saying more or less the same thing. Recall that, according to EMS, "Hume says that the self, insofar as it is accessible through inner experience, consists of nothing but the perceptions" and neither affirms nor denies the existence of a self beyond the perceptions (EMS 418, see also 421).

In his fourth objection, Wunderlich appeals to Hume's theory of ideas, following Tony Pitson's arguments against Galen Strawson (Wunderlich 552f.). As Wunderlich points out, for Hume there is no impression to which a contentful idea of a self beyond the perceptions could be traced. He emphasises, however, that Hume's account does not mean "that an entity such as a self beyond the perceptions [...] may not exist” (Wunderlich 553). Clearly, with this statement Wunderlich again expresses agreement with the reading in EMS rather than an objection. Wunderlich's point is, however, that "such an entity would be irrelevant to Hume's theory" as it would be "completely outside the reach of his theory" (Wunderlich 553). Here, we disagree. Hume's agnosticism about the existence of a self beyond the perceptions makes a huge difference. As explained in EMS 418-419 and 422, it means that some of the standard objections to Hume's account, such as the circularity objection, miss the mark. Moreover, limiting knowledge claims about the self to what is accessible to inner experience, without ruling out the existence of a self beyond the perceptions, makes room for appealing to such a self in matters that concern the passions and morality. EMS addresses this issue 
in the section that deals with Hume's account of personal identity "as it regards our passions or the concern we take in ourselves" (Treatise 253; EMS 423-428), relating to Books II and III of the Treatise and not discussed by Wunderlich. In Hume, issues to do with the passions and the ascription of praise and blame require a conception of the self as agent and subject rather than a mere bundle of perceptions. Such issues require the notion of "a person or creature endow'd with thought and consciousness" (Treatise 411; my emphasis), even if our theory cannot prove the existence of such a self beyond the perceptions. ${ }^{5}$ In terms then of the debate between the 'Old Hume' and the 'New Hume' readings, it is best to follow Alexander Pope's advice: "Regard not then if Wit be Old or New/ But blame the False, and value still the True" (An Essay on Criticism).

\section{References}

Cottingham, John (1976), 'Introduction', in Descartes' Conversation with Burman, ed. and transl. by J. Cottingham, Oxford: Oxford University Press 1976.

Davies, Catherine Glyn (1990), Conscience as Consciousness. The Idea of Self-Awareness in French Philosophical Thought from Descartes to Diderot, Oxford: Voltaire Foundation.

Descartes, René, Euvres de Descartes, ed. and transl. Ch. Adam and P. Tannery, 13 vols, (revised edn.), Paris: Vrin 1964-1976 [AT].

Descartes, René, Philosophical Writings, ed. and transl. J. Cottingham, R. Stoothoff, D. Murdoch, and A. Kenny, 3 vols., Cambridge: Cambridge University Press 1984-1991 [CSM].

Hume, David, A Treatise of Human Nature, ed. by David F. Norton and Mary J. Norton, Oxford: Oxford University Press 2000 [Treatise]. References are to the Selby-Bigge pagination, provided in the margins.

Hume, David, 'An Abstract of $A$ Treatise of Human Nature', in Hume, $A$ Treatise of Human Nature, ed. by David F. Norton and Mary J. Norton, Oxford: Oxford University Press 2000, 403-417 [Norton and Norton].

Locke, John, An Essay Concerning Human Understanding, ed. P. H. Nidditch, Oxford: Oxford University Press 1975 [Essay].

Renz, Ursula (2010), Die Erklärbarkeit von Erfahrung. Realismus und Subjektivität in Spinozas Theorie des menschlichen Geistes, Frankfurt a. M.: Klostermann.

Strawson, Galen (2011), The Evident Connexion. Hume on Personal Identity, Oxford: Oxford University Press.

Thiel, Udo, The Early Modern Subject. Self-Consciousness and Personal Identity from Descartes to Hume, Oxford: Oxford University Press 2011, Paperback Edition 2014 [EMS].

5 It is clear that in contrast to Book I (and contrary to what Wunderlich maintains on p. 551. footnote 18), Hume does not equate the person with the mind here but includes the body in his conception of the self (EMS 425). 